\title{
EL PASTORALISMO SARDO: ENTRE EL MERCADO GLOBAL, LA GESTIÓN DE LA INCERTIDUMBRE Y LAS FORMAS DE RESISTENCIA
}

\author{
Domenica Farinella \\ Università degli Studi di Messina
}

\section{Resumen}

La ganadería ovina es una de las fuentes principales de producción de Cerdeña, una isla en el corazón del Mediterráneo que, debido a su baja densidad de población y a sus vastos campos, es el terreno ideal para un pastoralismo extensivo. La extensión del sector fue impulsada por la demanda internacional de pecorino romano, un queso estandarizado, de bajo coste y elevada volatilidad de precio. Las empresas agropecuarias sardas, ya de por sí expuestas a la incertidumbre ambiental típica del pastoralismo extensivo, han aprendido a amortiguar y contener la inestabilidad económica procedente del mercado explotando mecanismos de resiliencia, adaptabilidad y redundancia típicas de lo que Ploeg define como una empresa campesina, es decir, una empresa orientada principalmente al mantenimiento y reproducción de los factores productivos propios más que a la venta para el mercado. La modernización agrícola se ha acoplado al modelo agropastoral tradicional, pero no sin ambivalencias y contradicciones que hoy parecen volver a emerger con cada vez más frecuencia destruyendo la capacidad del modelo agropastoral de adaptarse a la incertidumbre. En este artículo se intentará exponer esta tesis a partir de los datos recogidos en una extensa investigación etnográfica acompañada de entrevistas en profundidad, observaciones y material fotográfico obra de la autora. 
Palabrasclave: Modelo de agricultura campesina; pastoreo mediterráneo, incertidumbre, volatilidad de los precios de la leche, cadenas mundiales agroalimentarias, pastores.

\begin{abstract}
Sheep breeding is the most important agricultural activity in Sardinia, a rural island in the heart of the Mediterranean, which is the ideal territory for extensive sheep farming, thanks to its low population density and vast fields. The international demand for Pecorino Romano, a standardized cheese, characterized by low production cost and high price volatility, has driven the expansion of Sardinian pastoralism. The local agro-pastoral farms, already exposed to environmental uncertainties typical of extensive farming, have learned to contain the economic instability of international market, exploiting their mechanisms of resilience, adaptability and redundancy. Following Ploeg, they work as "peasant farms", i.e. farms mainly oriented to the maintenance and reproduction of its production factors rather than selling for the market. Agricultural modernization has thus grafted onto the traditional agro-pastoral model, with ambivalence and contradictions that today seem to re-emerge, depleting the ability of the agro-pastoral model to adapt to uncertainty. In this article, we will try to expose this thesis starting from the data collected in a long ethnographic research, accompanied by in-depth interviews, participatory observation, and photographic material.
\end{abstract}

Keywords: Peasant model of agriculture; Mediterranean pastoralism, uncertainty, milk price volatility, agri-food global chains, shepherds

\title{
1. LAS PROTESTAS POR EL PRECIO DE LA LECHE: LOS PASTORES SARDOS EN UNA ENCRUCIJADA
}

Es 6 de febrero de 2019 y hace ya un mes y medio que comenzó en Cerdeña la estación de ordeño. El precio de la leche está fijado entre 50 y 60 céntimos por litro de leche, y sin embargo, para cubrir los costes de producción, haría falta una remuneración de alrededor de un euro (Idda, Pulina y Furesi, 2010). La protesta nace en un clima de resignación y desconfianza, y da un giro totalmente inesperado: pastores de diversos puntos de Cerdeña abren los grifos de las cámaras frigoríficas de sus fincas y dejan correr la leche mientras se graban con el móvil. Otros pastores se encuentran en las plazas de los pueblos y tiran al suelo barriles de leche (Imagen 1). Los que no se atreven a dar ese paso extremo se graban mientras dan su leche a los cerdos de sus fincas o hacen queso con ella, reapropiándose del producto de su propio trabajo como acto extremo de una lucha que parece configurarse como una lucha de clases (ganaderos-trabajadores contra 
la industria). Las imágenes dan la vuelta al mundo. Los pastores organizan protestas espontáneas frente a numerosas centrales lecheras industriales y en los cruces de las carreteras principales: ningún camión lechero ni partida de queso debe circular por la isla, la producción ha de estar bloqueada (Simula, 2019; Farinella, 2019).

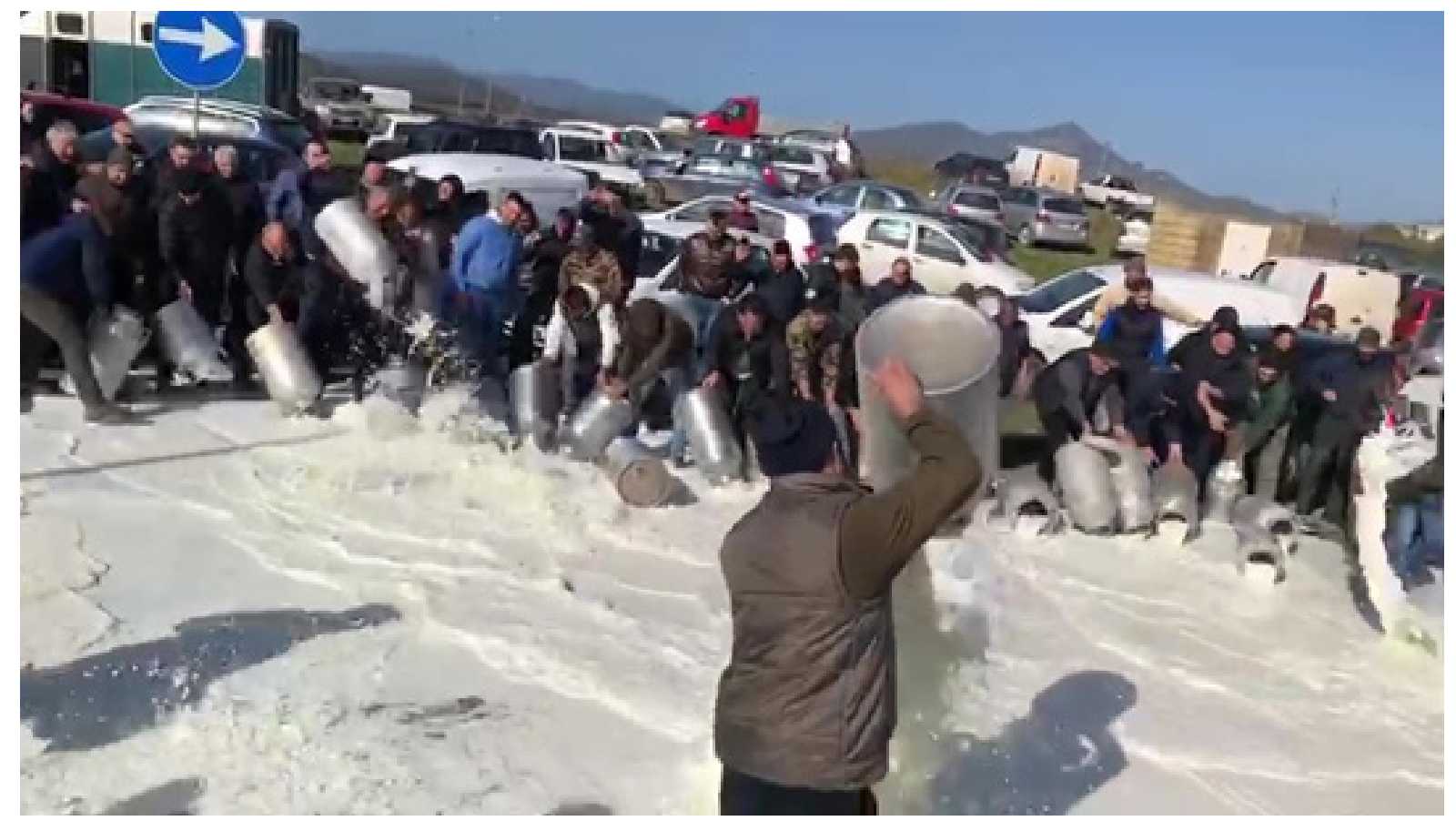

Imagen 1 - Los pastores tiran la leche a modo de protesta, febrero 2019

Fuente: fragmento de imagen sacada de un vídeo privado de un pastor

En Cerdeña, desde el año 2000, el precio de la leche se derrumba cíclicamente cada cinco años. Y sin embargo esta crisis llega al poco de la anterior; apenas dos años antes, en 2017, el precio ya disminuyó bastante, hasta 60 céntimos por litro. Esta fuerte reducción se vio agravada por el momento de dificultad que ya vivían las explotaciones, ya que en los meses anteriores habían sufrido un aumento imprevisto de sus gastos para comprar piensos, debido a que la persistente sequía había vuelto áridos los prados y perjudicado la producción de plantas forrajeras, reservas de alimentos y pastos. Además, los retrasos en la concesión de subvenciones comunitarias habían sumido a los ganaderos en una crisis de liquidez, exponiéndoles al endeudamiento. Tras varios meses de protesta en los municipios de la isla, esta culminó en una manifestación regional frente a la sede del gobierno el 2 de agosto de 2017, liderada por el Movimiento de Pastores Sardos. Inmediatamente después de esa manifestación se aprobaron medidas urgentes como la compra subvencionada del excedente de queso así como una indemnización de 13 euros por cabeza de ganado para paliar los efectos negativos de la sequía. Estas respuestas demostraron ser del todo insuficientes y el precio de la leche en 2018 no superó los 75-80 
céntimos por litro de leche. Las condiciones climáticas siguieron siendo desfavorables y no permitieron programar la producción de existencias e hicieron aumentar los gastos de forraje, heno y piensos. Por este motivo, las cuestiones sin resolver de la crisis de 2017 volvieron a estallar con virulencia en febrero de 2019.

Durante casi dos meses hay en la isla una movilización permanente, pero una vez más todo queda en agua de borrajas. Los pastores no consiguen unirse y formar un movimiento compacto que pueda reivindicar una plataforma común, y debido a un clima de creciente desconfianza en las organizaciones representantes históricas, los ganaderos se fragmentan y quedan atrapados en la espontaneidad. La campaña electoral para renovar primero el gobierno regional y luego el nacional engullen la protesta ganadera, que se convierte en un terreno de enfrentamiento político entre los diversos partidos. Las mesas de negociación reúnen a instituciones, industria y asociaciones de pastores sin llegar a un acuerdo. Lentamente la situación se normaliza: se invita a los ganaderos a volver a suministrar leche a la industria para no dañar más el sector y la protesta se alarga entre la remisión continua de decisiones entre las mesas y los tiempos dilatados de instalación de los nuevos gobiernos electos hasta que llega la temporada de verano cuando, como cada año, el rebaño se traslada a las zonas secas y se para la producción de queso. La protesta acaba implosionando por el hastío, sin que se haya acordado realmente ninguna medida de reforma del sector en un marco de incertidumbre e inestabilidad en el que los problemas simplemente se posponen hasta la campaña de 2020.

Los pastores, ya acostumbrados a un régimen de crisis recurrentes, se refugian en las tácticas amortiguadoras que adoptan espontáneamente cuando alguna crisis amenaza la supervivencia de las fincas para conseguir resistir esperando a tiempos mejores. El ahorro y el control de los costes hacen reducir las subidas de los animales y recurrir más a los pastos salvajes, provocando así una reducción del rebaño y de la cantidad de leche, y esperando que eso baste para superar la difícil situación en la que se encuentran (Farinella, 2018).

\section{LAS HIPÓTESIS DE LA INVESTIGACIÓN Y LA METODOLOGÍA}

El resumen de esta última crisis del precio de la leche en Cerdeña que empieza en 2017, y parece que sigue viva, nos permite adentrarnos en el núcleo de la cuestión pastoral sarda. La ganadería ovina es una de las fuentes principales de producción de Cerdeña, una isla en el corazón del Mediterráneo que, debido a su baja densidad de población y a sus vastos campos, es el terreno ideal para un pastoralismo extensivo. La extensión del sector fue impulsada por la demanda internacional de pecorino romano, un queso estandarizado, de bajo coste y elevada volatilidad de precio. Las empresas agropecuarias sardas, ya de por sí 
expuestas a la incertidumbre ambiental típica del pastoralismo extensivo, han aprendido a amortiguar y contener la inestabilidad económica procedente del mercado explotando mecanismos de resiliencia, adaptabilidad y redundancia típicas de lo que Ploeg (2013), siguiendo a Chanayov (1986), define como una empresa campesina, es decir, una empresa orientada principalmente al mantenimiento y reproducción de los factores productivos propios más que a la venta para el mercado. La modernización agrícola se ha acoplado al modelo agropastoral tradicional, pero no sin ambivalencias y contradicciones que hoy parecen volver a emerger con cada vez más frecuencia destruyendo la capacidad del modelo agropastoral de adaptarse a la incertidumbre. En este artículo se intentará exponer esta tesis a partir de los datos recogidos en una extensa investigación etnográfica acompañada de entrevistas en profundidad, observaciones y material fotográfico obra de la autora entre 2016 y 2019. Se realizaron más de 100 entrevistas a pastores sardos, trabajadores extranjeros y operadores del sector. En el próximo apartado analizamos las características del pastoreo en Cerdeña haciendo particular énfasis en las dinámicas que lo hacen depender de los precios de la leche. En el cuarto apartado evidenciamos cómo la modernización agrícola se ha acoplado al modelo agropastoral sardo y cuáles son los componentes de resiliencia que permiten a los ganaderos hacer frente a la incertidumbre. Por último, en la conclusión mostraremos por qué dichos componentes se ven cada vez más amenazados por los efectos negativos provocados por los procesos de modernización y por la dependencia cada vez mayor al mercado global.

\section{EVOLUCIÓN DEL PASTORALISMO SARDO Y DEL PRECIO DE LA LECHE}

El pastoralismo es un sector fundamental para la economía sarda. En 2016 había 13.004 explotaciones ovinas (el $27 \%$ de las fincas y el $25 \%$ de la facturación agropecuaria de la región), con un patrimonio de ganado de 3.369.379 (Istat, 2017), frente a una población de poco más de 1.600 .000 habitantes. En esta región se concentra el $48 \%$ del ganado ovino italiano, con una media de 259 cabezas de ganado, un valor mucho mayor al italiano, en torno a las 119 cabezas de media (Istat, 2017). Esta cantidad, no obstante, varía enormemente entre las zonas de llanura y las de colinas y montañas, donde de media, los rebaños son más reducidos. El pastoreo continúa siendo un buen recurso. Con él también se ha desarrollado una agricultura para la cría de animales mediante la producción de forraje, heno y pastizales para no comprar tanto en el mercado de las existencias de alimentos (imágenes 2,3 y 4). Según los datos del Instituto Nacional de Estadística Italiano (Istat) de 2013, más del $60 \%$ de la superficie agraria utilizada se destina a pastos y prados permanentes, frente a un valor medio nacional del 26,9\%. Por otra parte, las forrajeras representan el 58,7 \% de la superficie de la tierra de cultivo, mientras que a nivel nacional el porcentaje es solo un $28,8 \%$. 


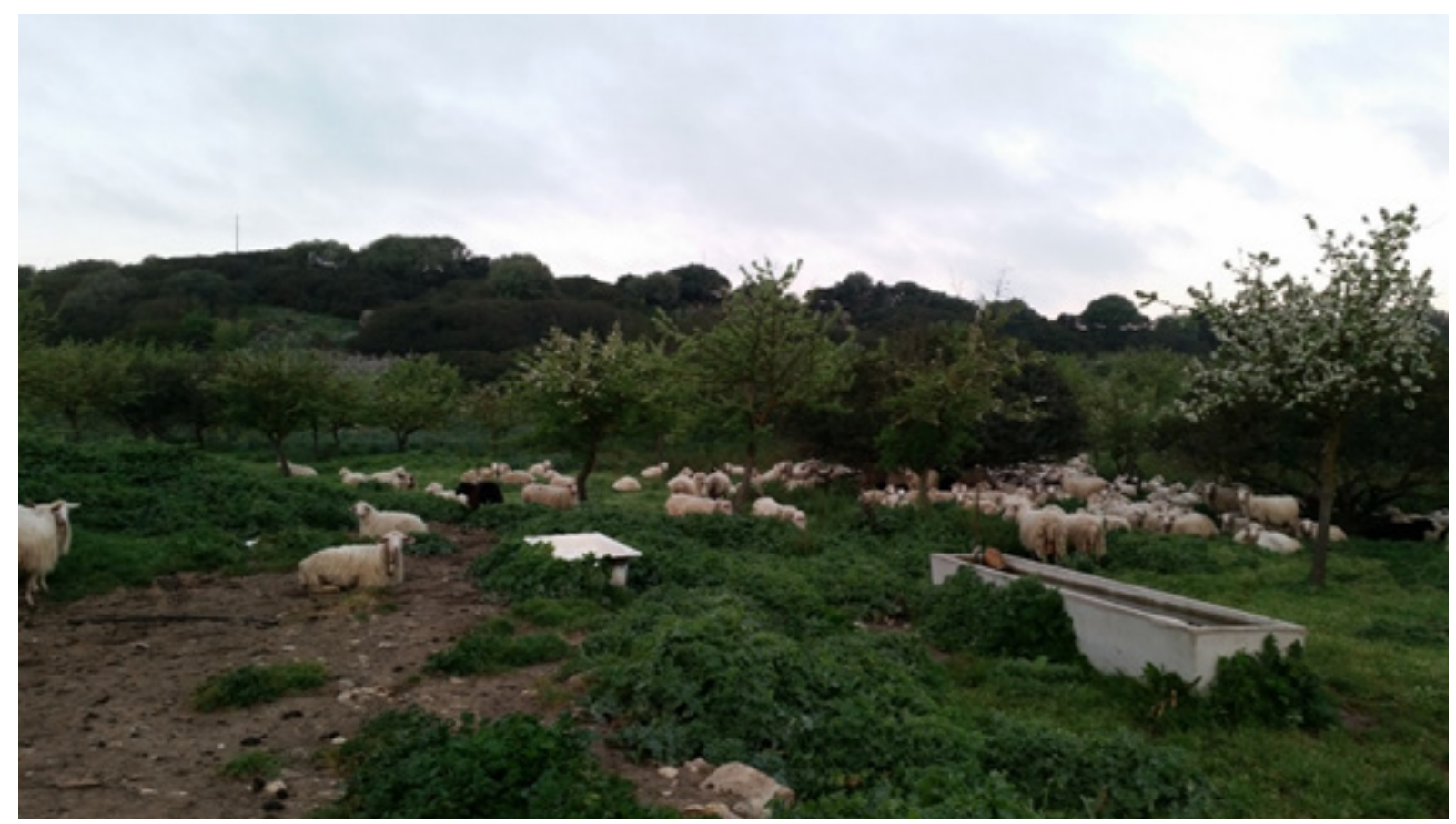

Imagen 2 - Ovejas en pastos naturales

Fuente: D.Farinella, granja de Orotelli, centro de Cerdeña, abril 2017

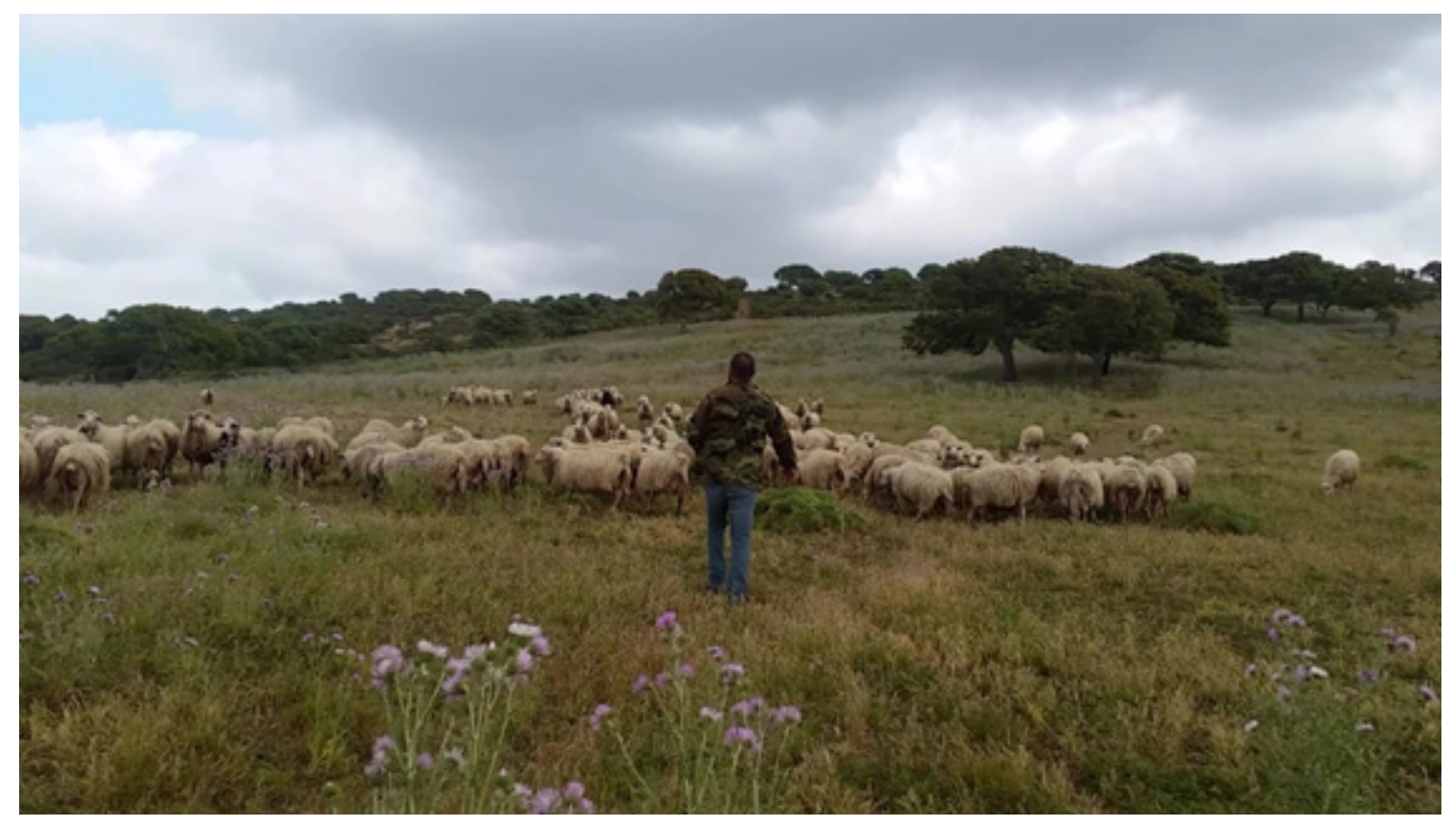

Imagen 3 - Pastor con ovejas en pastos naturales

Fuente: D. Farinella, granja de Villanova Monteleone, noroeste de Cerdeña, mayo 2017 


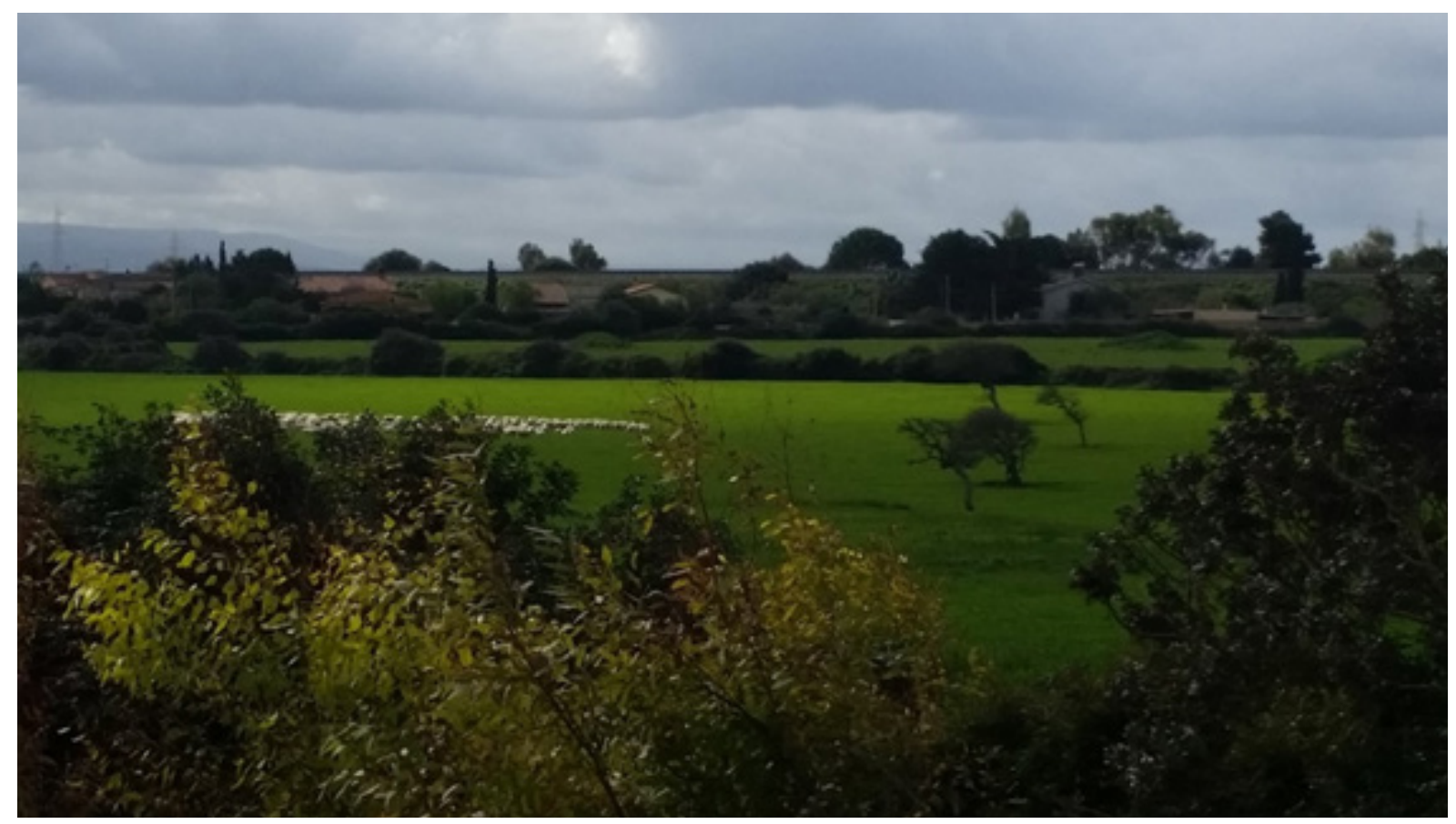

Imagen 4 - Ovejas en un prado cultivado

Fuente: D.Farinella, Porto Torres, noroeste de Cerdeña, febrero 2016

Más del 60 \% de las explotaciones ovinas crían también otras especies (Laore, 2013: 9), lo cual muestra que hay tendencia a diversificar los ingresos. La ganadería suele ser una buena posibilidad de empleo por cuenta propia en las áreas más interiores y rurales donde no hay muchas oportunidades laborales. La gestión familiar es un recurso estratégico: en más del $54 \%$ de los casos el propietario está empleado en la finca, mientras que en el $25 \%$ trabajan otros miembros de la familia (Istat, 2013). Este también es un nicho para los trabajadores migrantes (en su mayoría rumanos, pero también paquistaníes y norafricanos), principalmente presentes en las explotaciones medio grandes de las zonas de llanura. Este nicho se reduce considerablemente en las épocas en las que cae el precio de la leche. Son actividades manuales, de alta intensidad de trabajo vivo y el pastor realiza directamente todas las tareas, desde arar el terreno, pastar, cuidar y trasladar a los animales hasta ordeñarlos, e incluso producir queso cuando este se elabora en la finca.

Las explotaciones ganaderas se especializan en la leche. Con sus 2.860 .438 quintales en 2017, Cerdeña produjo el $67 \%$ de la leche de oveja del país, y el 14 \% de la de la Unión Europea a 28 países, en la que Italia es el tercer productor, tras Grecia y España, con una cuota del $21 \%$ (cálculos propios basados en los datos del Istat, 2017, y el Ismea, 2019). Esta leche se procesa en el territorio, en varias centrales lecheras industriales y privadas. Según el Istat (2017), hay en la región 74 unidades de producción que operan en el sector de los productos lácteos, de las cuales 53 son centrales lecheras y queseras, 2 instalaciones de explotaciones agrícolas, 17 cooperativas y 2 centros de recogida. A estas han de sumarse las numerosísimas minicentrales rurales en las que los ganaderos 
procesan directamente su propia leche para hacer quesos artesanales destinados a un mercado de nicho.

La transformación industrial fue impulsada por el pecorino romano, el único queso de oveja con relevancia nacional en un sector dominado por las producciones vacunas. Este representa de hecho la quinta denominación de origen italiana de quesos por volumen productivo y la tercera por valor de las exportaciones, precedido únicamente por el grana padano y el parmigiano reggiano. Según el Consorcio Pecorino Romano Dop (2015), Cerdeña produce el $95 \%$ del pecorino romano, que equivale a cerca del 50-55 \% de la leche que llega a las queserías locales de los pastores sardos, mientras el resto se transforma en pecorinos de maduración variable. Por este motivo, el precio de la leche depende del de este queso, dentro de un sector orientado a los mercados extranjeros. Según la Agencia Italiana para el Comercio Exterior (ICE), en 2017, el sector de los productos lácteos fue el tercer sector en exportaciones de Cerdeña, con un valor de 120, 489 millones de euros, precedido solo por los productos petrolíferos y químicos. El $70 \%$ de estas exportaciones se dirigían al mercado histórico, el mercado norteamericano. Este es uno de los puntos débiles del sector local, cuya suerte depende de la venta de un único producto en un único mercado.

La elaboración industrial del pecorino romano llegó a Cerdeña a finales del siglo XIX de la mano de unos productores del Lacio, a quienes les atrajeron las grandes existencias de leche (De Felice, 2011). Mediante una elaboración simple se conseguía un producto normalizado a bajo coste y apto para la exportación a larga distancia gracias a su maduración y estado curado. Precisamente por tener estas características, el pecorino romano cuenta con una buena posición en Norteamérica, donde cada vez es más demandado como queso de mezcla para dar sabor a los productos de la incipiente industria alimentaria, convirtiéndose así en un ingrediente para otras elaboraciones (Meloni y Farinella, 2015). Así se garantiza la venta a un mercado en crecimiento pero no se promueve el reconocimiento del producto por parte del consumidor final. A lo largo del siglo XX, en otras regiones meridionales de Italia, el pastoreo se vuelve cada vez más residual, mientras que en Cerdeña se expande en detrimento del resto de actividades agrícolas. El modelo agropastoral tradicional sardo cambia profundamente, estimulado por las presiones de la modernización agrícola (Mannia, 2014; Paoli 2018; Farinella, 2018).

Históricamente, las explotaciones agropastorales se concentraban en las zonas centrales e interiores de Cerdeña y se organizaban en torno a la unidad familiar, que garantizaba las funciones productivas y reproductivas según una división articulada del trabajo que pasaba por el género. Por una parte, el pastor trashumante que, por medio de la producción yventa de queso, garantizaba la entrada de dinero. Por otra parte, la cónyuge se ocupaba de las actividades reproductivas del núcleo familiar enmarcadas en la economía 
doméstica, donde había un fuerte cultivo mixto caracterizado por la ganadería mixta (en particular cabras, ovejas, vacas y cerdos), la agricultura extensiva para el autoconsumo centrada en la producción de cereales y la presencia complementaria de vid y olivos (entre otros, Le Lannou, 1979; Ortu, 1981; Meloni, 1984; Angioni, 1989; Murru Corriga, 1990; Mattone y Simbula, 2011).

La ganadería ovina se basa en el pastoreo libre como estrategia de bajo coste. Una cabeza de ovino que pasta libremente necesita de media casi una hectárea de tierra al año para ser criada. A finales del siglo XIX se contaban casi dos millones de cabezas de ganado variado, y casi la mitad eran ovejas. La isla cuenta con una superficie rural de casi 2400000 hectáreas, y la ganadería ovina comparte ese territorio con la agricultura, con la que el equilibrio es inestable y conflictivo (Ortu, 1981; Meloni, 1984; Corriga, 1990; Farinella y Ibba, 2020). Para contener las tensiones entre agricultura y pastoralismo, se implementó un complejo sistema de gestión del territorio que preveía una rotación de los terrenos, el realce de los terrenos comunes (Meloni, 1996) y la organización trashumante del pastoreo (Meloni, 1984; Ortu, 1988) que implicaba el traslado del rebaño de las áreas más interiores hacia las llanuras del norte y del sur (Le Lannou, 1977). Durante su trashumancia, los pastores improvisaban apriscos y transformaban el queso en dos elaboraciones principales: por un lado el fiore sardo, destinado a un mercado extralocal, sobre todo el sur de Italia y Francia, y que vendían mediante una densa red de intermediarios, y por otro, el pecorino sardo, para vender en el mercado local de las familias que se encargaban de las existencias de alimentos, o para autoconsumo. La introducción de la elaboración industrial cambia profundamente el trabajo de los pastores, que dejan de convertir la leche en queso y se especializan solo en la producción de leche, convirtiéndose así en proveedores de la industria (De Felice, 2011).

Además, a partir de los años 50, la agricultura sarda tradicional, organizada de forma extensiva y de bajo rendimiento, entra en crisis debido a la llegada de los cereales extranjeros de bajo coste y productos envasados de la industria alimentaria. Los terrenos agrícolas abandonados los van adquiriendo lentamente los pastores, que se apoderan de las llanuras y de los caminos históricos de la trashumancia, creando así las explotaciones modernas (Mannia, 2014; Meloni y Farinella, 2015). Mediante las diversas oportunidades de financiación, los ganaderos se preparan para responder a la creciente demanda de leche por parte de la industria (Pulina y Biddau, 2015): aumentan el rebaño, compran jaulas para los animales, ordeñadoras mecánicas y refrigeradores para conservar la leche, terrenos y maquinaria agrícola para cultivar y construyen graneros para los alimentos y cuadras para el ganado. También empiezan a seleccionar genéticamente para aumentar la productividad de la oveja sarda, una raza autóctona pequeña que consume poco y se adapta a los pastos silvestres pero que es menos productiva que las razas de cuadra. 
"Cuando empezamos con la explotación, teníamos 120 ovejas que el padre de Giovanni le había dado, y habíamos alquilado estas 18 hectáreas. En esos años nos centramos en comprar tierras, no solo las que teníamos alquiladas sino también otras porque queríamos crecer, ya que con esa extensión no hacíamos nada. Así que durante esos años intentamos comprar tierras, aumentar el rebaño, para finalmente llevar a cabo este proyecto de mejora del suelo, cobertizo, ordeñadora, y todo eso, porque parecía que ese debía ser el futuro del pastoralismo. En esos años nosotros también empezamos a acoger machos seleccionados, a seleccionar el rebaño para que fuera más productivo, etc." (Julio 2017, entrevista a ganadera, Ittiri, noroeste de Cerdeña)

Si bien estas innovaciones mejoran la calidad del trabajo, también hacen que el pastor dependa más del mercado, tanto por su productividad (venta de leche) como por sus insumos, ya que por ejemplo el pienso se convierte en un elemento indispensable de la dieta de la oveja, tanto para que entre en la ordeñadora como para mantener el aumento de producción. Eso hace que también aumenten los gastos de electricidad, agua, combustible, estiércol, y también los de veterinaria y selección genética.

Además, el sector de la industria del pecorino romano, si bien sostiene la extensión del pastoralismo, también es la base en la que se apoyan las crisis recurrentes. De hecho, el pecorino romano es un queso de bajo valor añadido, imitable, sujeto a una competencia barata y dependiente del mercado norteamericano, cuyo acceso controlan pocos intermediarios que desempeñan un papel verdaderamente monopolista. Las pequeñas y medianas empresas de transformación sardas, sobre todo las cooperativas de pastores, producen partidas de queso que luego se venden a mayoristas e intermediarios, sin ninguna capacidad de incidir en el precio. Este carácter subalterno se reproduce también en el sector de la gran distribución organizada, donde el pecorino romano se vende al corte y también rallado en las mezclas de quesos, como alternativa picante al grana padano o al parmigiano reggiano. Unas pocas grandes cadenas de distribución y algunas grandes empresas nacionales de transformación controlan el sector y consiguen adquirir las existencias de pecorino romano a la baja, debido a la elevada fragmentación de los productores locales y a la elevada intercambiabilidad del producto con otros competidores directos, como los pecorinos genéricos u otros quesos de vaca (Farinella, 2018, 2019).

Hasta finales de los noventa, el mecanismo comunitario de la devolución de las importacioneshabíamantenidoartificialmenteelpreciodelpecorinoromano,permitiendo su venta a precios competitivos en Estados Unidos y, al mismo tiempo, redistribuyendo a lo largo de todo el sector las compensaciones recibidas de las devoluciones (Idda, Furesi y Pulina, 2010b). Desde principios de los años 2000, la desaparición de este mecanismo ha vinculado el precio del pecorino romano, y por consecuencia, el de la leche de oveja 
sarda, a la evolución inestable del mercado, dando pie a caídas recurrentes en los precios que en los últimos años han sido cada vez más frecuentes, como evidencia la imagen 5.

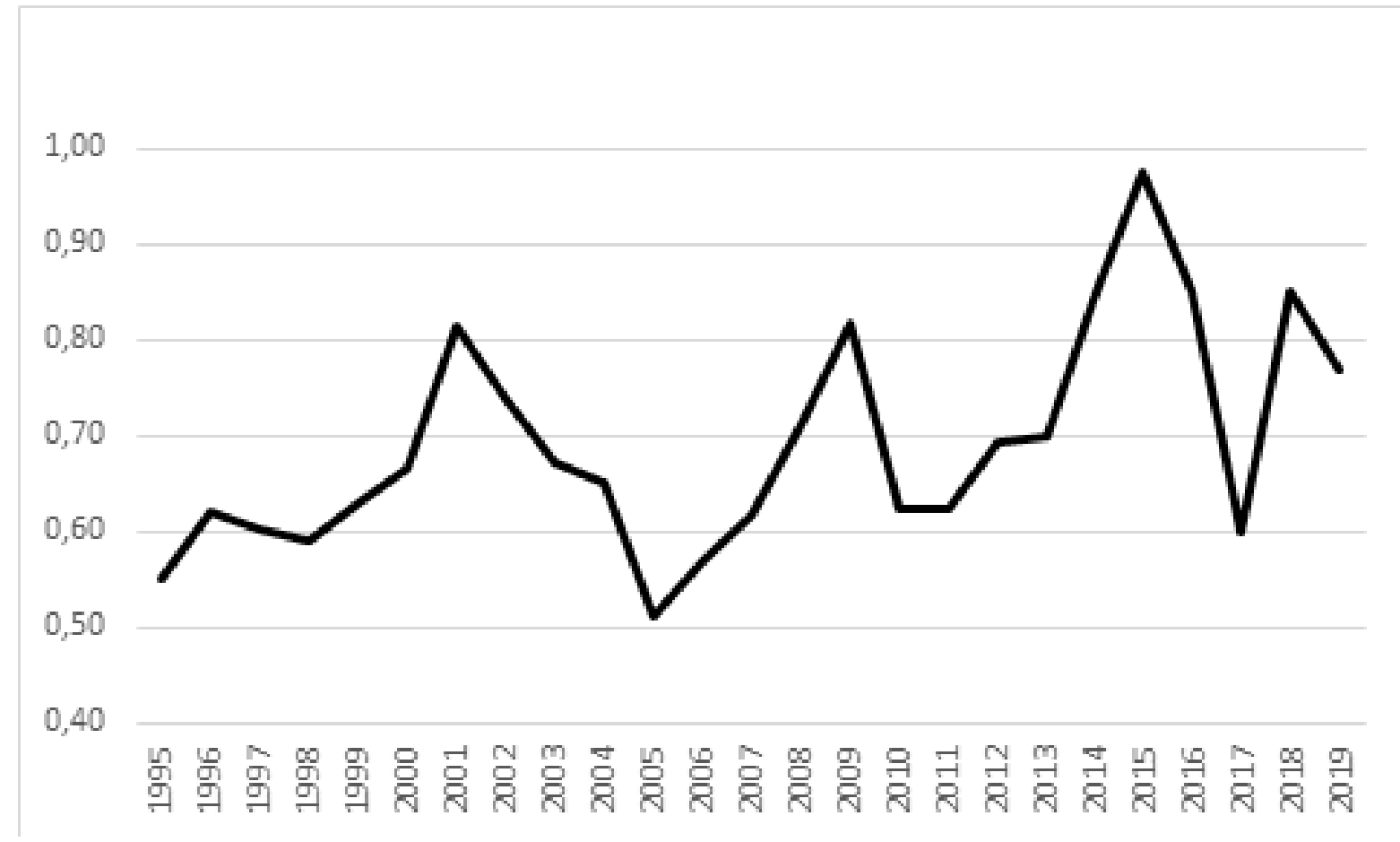

Imagen 5 - Evolución del precio de la leche de oveja en Cerdeña, años 1995-2019

Fuente: Elaboración de datos del Instituto de Servicios para el Mercado de Alimentos Agrícolas (ISMEA)

Los actores más débiles de la cadena (ganaderos y transformadores locales) agravan la situación al adaptarse al ciclo inestable del pastoreo. Cuando se registra un aumento del precio de la leche y del pecorino, los ganaderos, motivados por potenciales ganancias, invierten para producir más leche, previendo un aumento del rebaño para la siguiente campaña y de la producción por cabeza de ganado. Esto último se consigue con una mayor selección y una alimentación más cara, con piensos concentrados y complejos. Los productores también quieren hacer más pecorino romano, porque con precios sostenidos, da mayores beneficios que otros productos. En poco tiempo se alcanza un pico de producción que provoca un colapso del precio:

"E. ¡Con la misma podríamos sacar la leche del mercado! ¡A 50 céntimos nos conviene sacar la leche del mercado! ¡No derramarla! Aunque si la tiramos quizá es mejor...

T. Sí, pero el discurso es el de siempre, cada vez que baja el precio, todos dicen de sacar la leche del mercado, ipero al final todos la dan! ¡Todos! ¡Todos ordeñan! ¡Y no ordeñan solo una vez! Todos ordeñan... ¡hasta tres veces! Y al final el problema es solo nuestro, de los que hemos creado este mercado, jnosotros y las cooperativas industriales! [...] Nos hemos equivocado nosotros, si es que ha sido una equivocación, de las cooperativas, es que el pecorino romano hasta los últimos años se hacía el $40 \%$, 
alguno hacía el $50 \%$, pero desde hace dos años el precio ha petado, ¡todo romano! ¡Todo! Ya sabes que en Cerdeña se exportaban 300 mil quintales de pecorino romano; este año son 500 mil quintales, así que es normal que digamos que el mayorista tiene donde elegir, ¿no? Si tú se lo das a siete, ¿va a comprar el mío a 10?

E. Otro pastor: ;tiene donde elegir para la venta, entendido!

T. ¡Hay demasiada materia prima! ¡Ese es el problema! [...] ¡Hay en exceso! ¡Todas han hecho romano! ¡Todas romano! [...] Luego, si el precio de la leche aumentó el año pasado... Los pastores han sembrado y cultivado de más, han empujado mucho a las corderas, han producido más leche... ¡cómo no va a haber exceso! ¡Es normal que lo haya!

E. ¡También hay exceso de ganado!"

(Octubre 2016, discusión entre dos pastores sobre la crisis del precio que se planteaba para 2017, Sarule, centro de Cerdeña)

Las explotaciones van lentamente adaptando sus decisiones para responder a la crisis. Los productores tratan de diversificar su producción a quesos alternativos al pecorino romano y los ganaderos eligen estrategias económicas de reducción de costes: ajustan el tamaño del rebaño y la producción media por cabeza de ganado, vuelven al pasto como alimento central de la dieta del ganado y disminuyen la inversión en agricultura. Naturalmente entonces disminuye la cantidad de leche que circula y el porcentaje de leche que se transforma en pecorino romano. Se crea una nueva tendencia positiva que sin embargo morirá cuando los precios elevados de la venta empujen de nuevo a los pastores a reorientar sus decisiones hacia una mayor producción.

A primera vista, los ganaderos parecen tener un comportamiento extremadamente individualista y a corto plazo, parece ser corto de miras y contraproducente. No obstante, en realidad, estas decisiones se enmarcan en el modelo de funcionamiento más general del pastoralismo sardo, una actividad que está naturalmente expuesta a una incertidumbre múltiple y diferenciada, que depende de otros factores como son el ambiental, climático, institucional, económico y relacional (Scoones, 2019; Nori, 2019). Como veremos en el próximo apartado, para contener las fuentes de incertidumbre, los ganaderos aprenden a planear la explotación con miras a un futuro que sigue siendo contingente, y en función de su mutabilidad, reorganizan constantemente su actividad.

\section{ANCLAJE A UN FUTURO CONTINGENTE Y ESTRATEGIAS PARA CONTENER LA INCERTIDUMBRE}

"Aquí estamos, y te lo digo siempre, en manos de Dios, de la burocracia y de todas esas cosas, porque somos un oficio que va a ciegas. No puedes decirte "ah, pues este año, total de ingresos $y$ de capital $x$ ", porque igual sales con las ovejas y se enferman, hay hierbas pero se enferman las ovejas y vas de culo. En los años que igual las ovejas 
están sanas hay una cosecha de mierda y gastas para recuperar la cosecha de mierda. Cuando las ovejas están sanas y hay buena cosecha no te pagan la leche, y estás siempre en la casilla de salida. Es un oficio en el que nunca tienes seguridad, nunca hay seguridad económica porque es un oficio al que le acompañan muchos imprevistos". (Septiembre 2016, entrevista a ganadero, Orune, centro de Cerdeña).

Como subraya el entrevistado, el ciclo del pastoreo y sus modalidades organizativas hacen que esta actividad sea frágil y esté expuesta. La temporada de producción de leche empieza a finales de noviembre con los primeros partos y acaba en julio. El pastor organiza su actividad sabiendo que en el periodo seco de las ovejas, de mediados de julio hasta mediados de noviembre más o menos, estas son un coste. Sobre todo si se tiene en cuenta que muchas están embarazadas y deben alimentarse adecuadamente. Además, hay que tener en cuenta los gastos vinculados al inicio de la actividad agrícola para producir pastizales y forrajeras. Los beneficios de la venta de la leche en los meses de producción deben cubrir también los meses en los que la oveja es "pasiva", por usar una palabra de jerga corriente. Es un equilibrio delicado en el que el mínimo imprevisto puede tener efectos desestabilizantes. La caída repentina del precio de la leche, o el del cordero (en el periodo navideño es la fuente de ingresos principal), una pelea con un vecino que causa problemas en la gestión de los terrenos y de los pastos, una enfermedad imprevista que impide trabajar en una profesión en la que el rebaño va siempre acompañado, un retraso en los pagos comunitarios o un préstamo denegado, una cosecha que sale mal por la sequía o una nevada imprevista, un incendio que pone en peligro al ganado que está pastando, enfermedades inesperadas que pueden provocar una reducción de leche (como las mastitis) o la aniquilación del rebaño (como la lengua azul). Prácticas burocráticas que para resolverlas hay que dedicar menos tiempo al trabajo agrícola, creando costes adicionales. Una alimentación equivocada o un suceso estresante que hace que la producción de leche de las ovejas disminuya. El descuido de las operaciones de limpieza normales que acaba contaminando la leche, con penalizaciones por parte de las empresas de transformación. La avería del equipo, por ejemplo del tractor durante el periodo de arado, o de la cámara frigorífica, con el riesgo de que se ponga mala la leche. Estos son solo algunos de los imprevistos que amenazan a diario la vida del pastor y aumentan los costes de gestión de la explotación que anoté en mi diario de campo, a partir de las historias de los ganaderos.

La incertidumbre se reestructura como evento externo, imprevisto, incontrolable, que obliga al pastor a organizar su actividad en función de dos ejes: ir sobre seguro en los momentos de éxtasis ganando más, y prepararse para poner en marcha tácticas rutinarias (De Certeau, 1990) útiles para protegerse y sobrevivir en las fases de crisis. Esto implica reinvertir todos los recursos en la explotación, recursos económicos, materiales y 
relacionales con la familia, eliminando la distinción entre vida laboral y personal, entre producción y reproducción. El oficio de pastor es un modo de vida que se acepta y al que uno se adapta junto con todo el núcleo familiar, que supone la cámara principal de compensación de riesgos:

El oficio de pastor es difícil porque [...] no es solo un oficio, es una forma de vida, lo has de implementar como forma de vida. Ser pastor no es como otros oficios en los que puedes cerrar a una hora y ahí lo dejas. El oficio de pastor es una forma de vida, desde por la mañana hasta por la noche con todos sus pros y contras iy has de aceptarlo al $100 \%$ ! [...] Tipo que se trabaja todos los días sin descanso, comer a determinadas horas, volver a casa con los zapatos sucios... O sea, no puedes decirle a tu marido antes de entrar a casa "quitate los zapatos que me ensucias el suelo, antes de salir te los vuelves a poner y ya". Son peticiones estúpidas para nuestra profesión porque él entra $y$ sale de la finca a todas horas, no puedes estresarte, itienes que aceptar las cosas como son! [...] Tienes que aceptar que a nivel económico a veces hay dinero y a veces no, a veces puedes ir a hacer la compra y a veces no, y debes adaptarte, qué sé yo [...]. A veces necesitas dinero y no hay, [...] ipues te adaptas y te montas un huertito! (Julio de 2017, entrevista a ganadora, Sant'Andrea Frius, sureste de Cerdeña)

La organización de la matriz familiar es un recurso resiliente porque permite mantener la alta intensidad del trabajo manual y crear valor recurriendo a parientes empleados ya sea ocasionalmente o permanentemente (más hermanos, padres e hijos, tíos y sobrinos, marido y mujer). Además da pie a formas de multiactividad (permite que los miembros de la familia realicen tareas extraagrícolas) y de multifuncionalidad (diversificación de las actividades agrícolas) que permiten que haya una diversificación de los ingresos (Roep y Ploeg, 2003; Ploeg, 2008) y que disminuya la dependencia de la explotación únicamente a la venta de leche a la industria. Estos aspectos están bien reflejados en este extracto del diario de campo.

Apenas son las 7. Llega D. (hermana del ganador propietario, nota propia) con el rebaño que acaba de ordeñar y descarga la leche. [...] D. es cocinera, graduada en hostelería, y ahora está haciendo un curso de tallado [...]. En la finca trabajan todos: D. y el sobrino han ordeñado, A. (ganadero propietario) también ordeñó conmigo, pero en otra parte de la explotación, porque las ovejas están organizadas porgrupos. El padre, que de hecho está jubilado y tiene algunos problemas de salud, sigue trabajando. Por la mañana, a las 7 ya está en el aprisco, listo para hacer queso y requesón, ya ha preparado el hornillo, la olla y el resto de herramientas. El padre, mientras hacemos queso, me repite que todos trabajan cuando pueden en la explotación: el nieto viene a trabajar siempre cuando no tiene clase, D. también trabaja fija en la explotación cuando no hace la temporada, porque también es ayudante de cocina en los meses de verano en un hotel del norte de Cerdeña. También trabaja el hermano mayor de A. 
en la explotación. No a jornada completa porque tiene un bar en la ciudad y lo lleva él. En el aprisco, los dos trabajadores fijos son A. y él, pero todos arriman el hombro. Han de aprender a hacerlo todo, me repite.

Más tarde, cuando voy a casa de A., me doy cuenta de que toda la familia trabaja a pleno rendimiento para "mantener" la finca: la madre hace pasta artesanal rellena $y$ dulces sardos típicos con base de queso, además de galletas sardas tradicionales y embutidos varios, todo en casa. Luego los vende informalmente a los vecinos. Otra hermana que trabaja como empleada en Nuoro se encarga de todas las cuestiones burocráticas vinculadas a la actividad; ella va a hacer el papeleo.

A. me explica que él ha de ir a ordeñar al alba (de hecho nos levantamos a las 4:30 de la madrugada) porque necesita hacer el queso muy pronto: para las 8:30 la ricotta, que se hace con los restos de la elaboración del queso, ha de estar lista para repartir a las diversas tiendas de alimentación de la zona a la que suministran.

Cuando A. sale a repartir la ricotta, llega al aprisco el camión de la leche, porque A. diversifica. Una parte de la leche se la hace llegar a Pinna, la principal empresa de la industria sarda, y otra parte la transforma directamente en queso y lo vende en el circuito del territorio que se ha ido construyendo poco a poco.

El chico del camión de la leche es de S., un pueblo cercano, y me explica que trabaja para Pinna como propietario-usuario; el furgón de transporte de leche es suyo y Pinna le paga parte por la leche y otra parte por kilómetro. Empezó su ronda a las 5:30, la primera recogida fue a las 5:50. Recoge en toda la zona hasta Orune, y cuenta con llegar a Thiesi (donde está Pinna) antes de las 11:00. Luego ha de esperar casi dos horas para descargar. Antes hacía dos rondas, pero este año con la crisis solo hace una. Le pregunto qué hará cuando haya terminado y me dice que cuando termina de repartir la leche, vuelve al pueblo y se va a la finca para ayudar a su padre, que ahora tiene ovejas. Me explica que hasta el año pasado, trabajaba en la cooperativa de Bortigali (hacía la temporada), y su padre tenía el furgón y hacía las entregas a Pinna. Ahora, su padre está jubilado y sigue trabajando en el campo con las ovejas, y él ha tomado el puesto de su padre con el furgón. (Diario de campo, 9 de abril 2017, Orotelli, centro de Cerdeña).

Muchos ganaderos tienen también otros trabajos y además dedican una parte de su producción al autoconsumo o al intercambio local dentro de los circuitos de reciprocidad. Esto les permite anclarse al territorio para crear valor. Los pastores durante las visitas me muestran con orgullo sus existencias de productos agropecuarios: conservas, vino, aceite, pan, carnes, embutidos varios, quesos, productos de la huerta... (Imágenes 6, 7 y 8). Como dice uno de los ganaderos, incluso cuando hay pocos beneficios, "ide hambre no morimos!". 


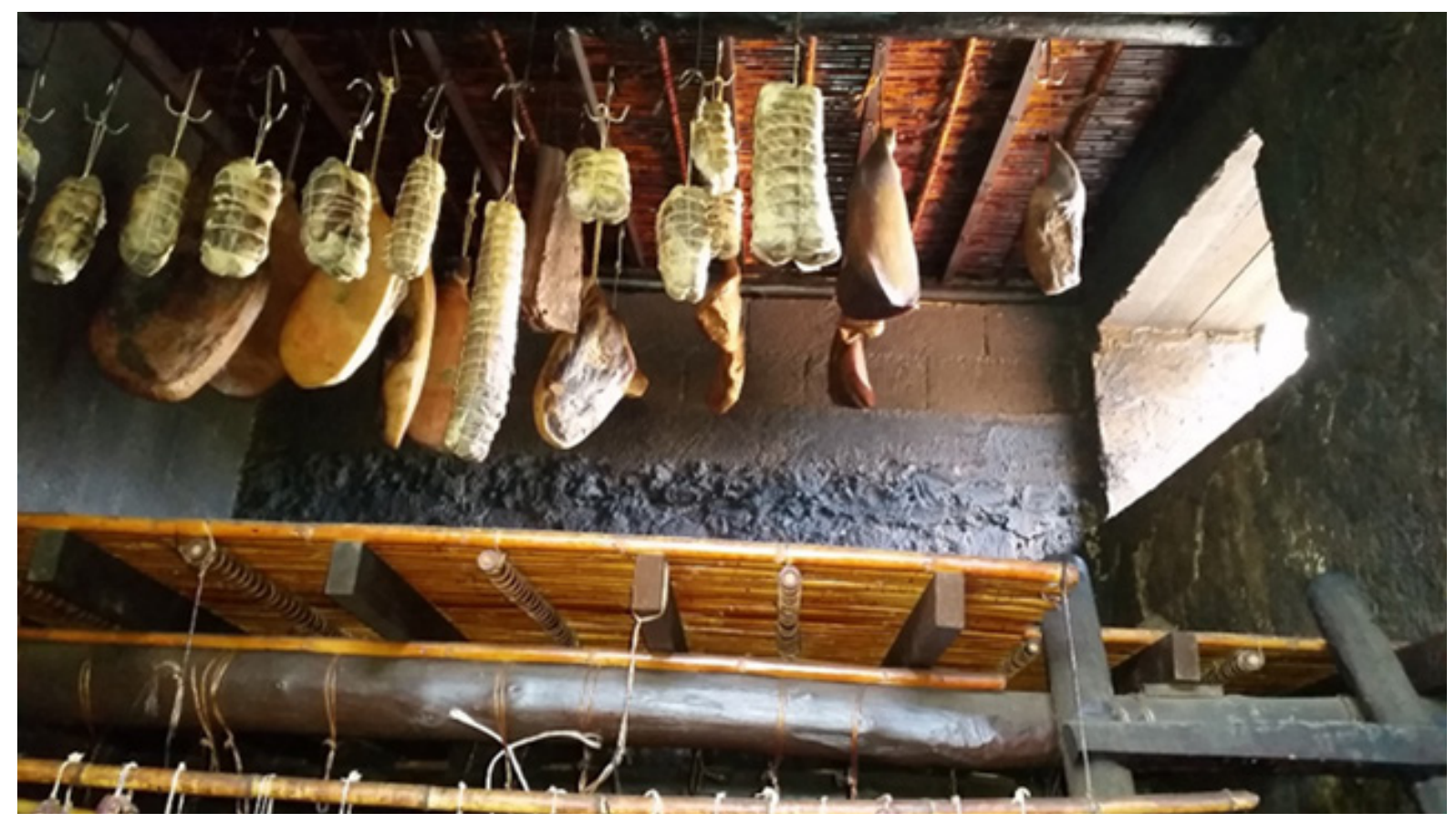

Imagen 6 - Autoproducción de fiambres y embutidos

Fuente: D.Farinella, granja de Bonacardo, centro-oeste de Cerdeña, abril 2015

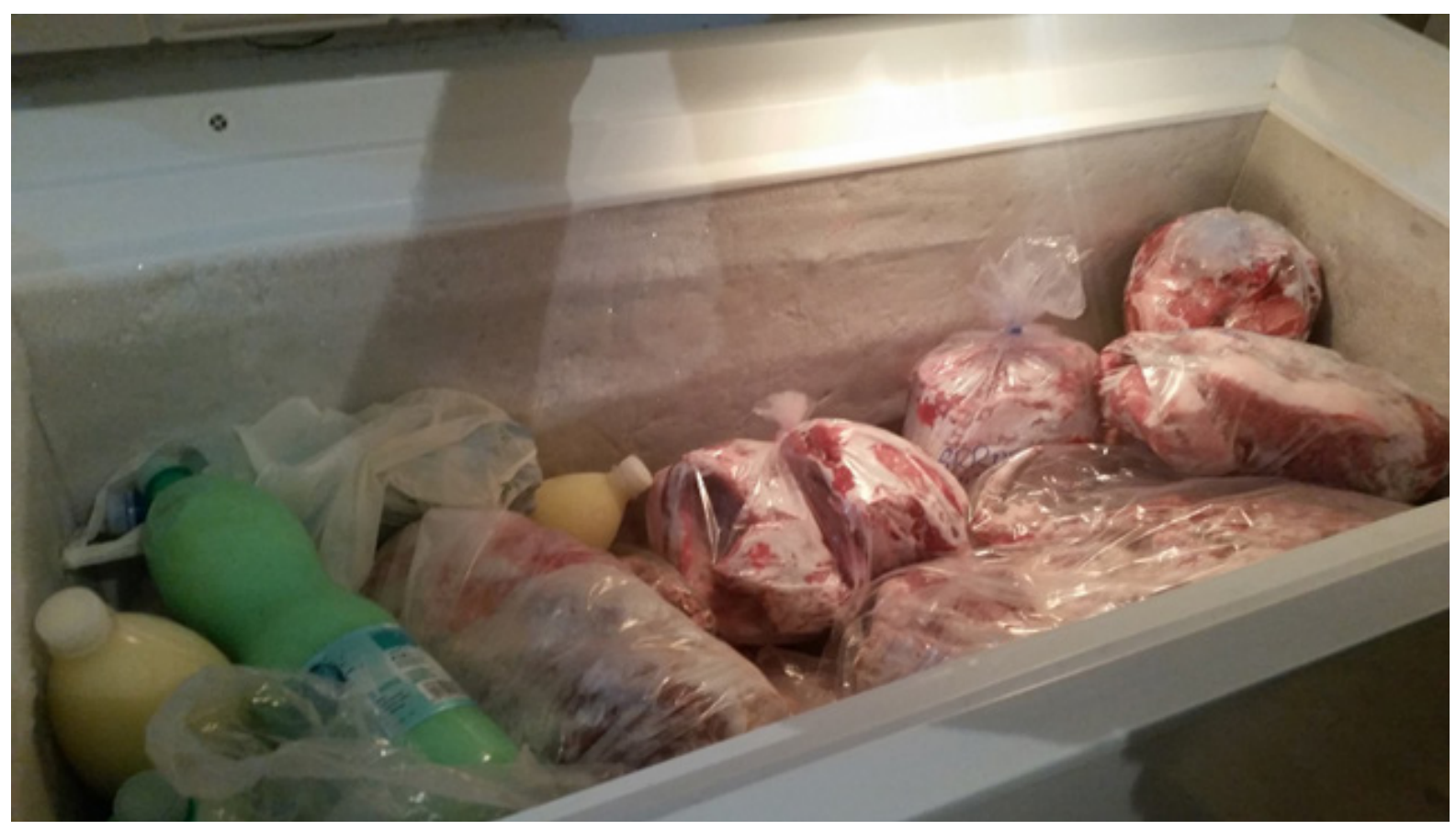

Imagen 7 - Provisiones de carne de varios tipos

Fuente: D.Farinella, granja de Talana, centro-este de Cerdeña, marzo 2017 


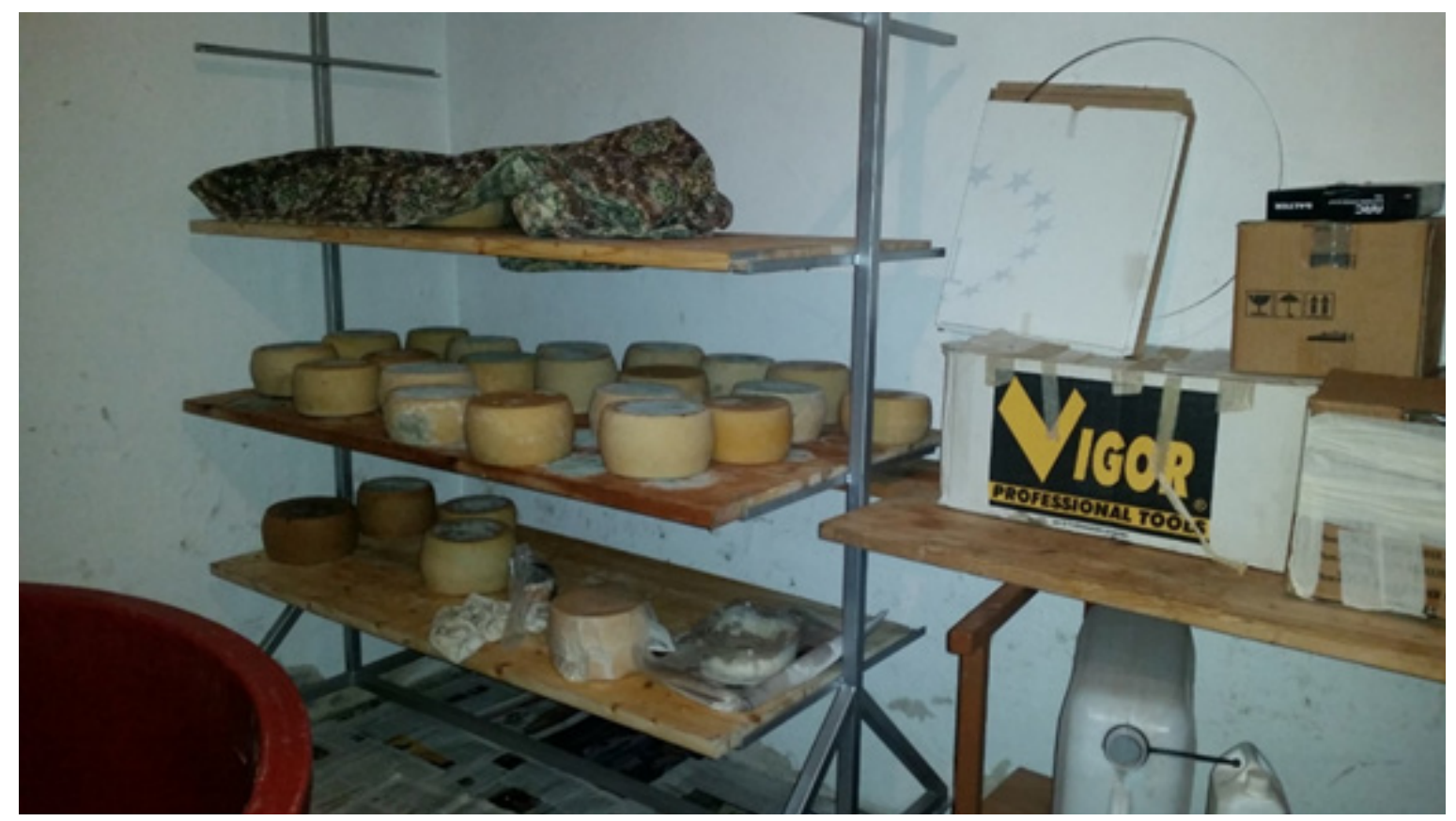

Imagen 8 - Producción de quesos para el autoconsumo

Fuente: D.Farinella, granja de Talana, centro-este de Cerdeña, marzo 2017

La organización familiar es también una manera de compartir los riesgos y aumentar las oportunidades de financiación gracias a que una gran explotación familiar está siempre compuesta de unidades empresariales formalmente separadas. Se utilizan diversas tácticas para aprovechar las oportunidades que se van presentando. Por ejemplo, la capacidad de financiación mejora gracias a que más familiares (por ejemplo el hijo o la mujer) pueden acceder en años diversos a los incentivos para los jóvenes agricultores. Asimismo también es posible "hacer malabares" con la leche entre las distintas empresas para maximizar los ingresos. Un ganadero, por ejemplo, me contó que él suministra a una cooperativa mientras que su hermano a una empresa privada y varía la cantidad de leche de una empresa a otra en función de cuál pague mejor. En otro caso, dos hermanos titulares de una explotación acordaron lo siguiente: uno de los dos se haría socio de una cooperativa, cuida a las ovejas de los dos y las ordeña, y suministra la mayor parte de la leche. Si tiene beneficios, el otro hermano, que está más implicado en otras actividades (corcho y producción de miel), transforma una parte de la leche en queso y se queda con los beneficios de la venta.

La inseguridad forma parte del día a día en la finca, que siempre se proyecta con fuerza en un futuro próximo de contingente variable respecto al cual deben de orientarse de forma sensible y adaptable todas las decisiones de la explotación. La unidad familiar opera así dentro de un binario doble marcado por eventos a corto plazo. En las fases de crecimiento económico en las que la leche se paga bien, toca expandirse y ampliarse para consolidarse, trabajando como una empresa orientada al mercado y a los beneficios. En 
las épocas de crisis, es necesario activar mecanismos de compensación de riesgos que permitan seguir resistiendo/existiendo. En ambos casos, el pastor nunca está inmóvil ni pasivo frente a los momentos inciertos. Siempre estudia tácticas rápidas para sacar el máximo partido a su posición en contextos que percibe como abiertos o inestables, actuando según un cálculo individualista y familiar cuyo objetivo es maximizar y proteger los intereses de la empresa y la familia.

Por este motivo, los ganaderos complementan esos componentes tradiciones del modelo agropastoral que permiten crear un valor real (no necesariamente monetizable) como el autoconsumo o el pasto con nuevas oportunidades de ingresos que nacen de procesos de modernización, introduciéndose por ejemplo en el sector de la selección genética o valorando las posibilidades de inversión de la ganadería estabular con ovejas assaf o cabras españolas, sin duda más productivas que las razas locales y también más fáciles de llevar, ya que no van de pastoreo.

L. es de Austis, es ganadero bovino y también se dedica a la selección genética. Es representante de venta de esperma seleccionado, y me cuenta que este mercado está en auge porque en vez de comprar un toro seleccionado, que es carísimo y te arriesgas a que se te muera, es mucho más conveniente comprar el esperma seleccionado y hacer la monta artificialmente. [...] Pero L. también se dedica a tres mil cosas más: hace miel y la vende, trabaja el corcho y la leña. También construye redes de contactos. Hoy por ejemplo ha venido a la fiesta de Seulo donde ha quedado con unos amigos y ha traído pan y galletas de Austis. Tenía el coche lleno, me ha regalado hasta a mí. Es el principio del "s'aggiudu torrau" sardo, "ayuda restituida" que expresa la lógica de la reciprocidad y es el motivo principal del regalo. (Diario de campo, Seulo, sur de Cerdeña, 9 abril 2017, fiesta de S'Orrosa 'e Padenti).

Si a la larga los esfuerzos hacia la modernización y los componentes agropastorales acaban contradiciéndose, el pastor, que proyecta a corto plazo, de cara a un futuro contingente solo tiene estrategias mediante las cuales, en función de las necesidades, se puede ganar más o ahorrar algo. La lógica que le rige es experimentar y explorar: un esfuerzo que implica estar alerta para aprovechar los primeros indicios de inversión de la tendencia y suspender la táctica al primer indicio de fracaso.

He de decir que los pastores no esperan sentados a que la crisis les caiga encima. Siempre están pensando en estrategias para incrementar beneficios o responder a situaciones de crisis como es la reducción del precio de la leche. Por ejemplo, muchos me dijeron que sustituir a las cabras sardas por las españolas fue una idea que surgió para aumentar la productividad de sus inversiones, ya que una cabra española produce mucho más que la raza autóctona y además es mucho menos exigente ya que está en la cuadra y no hay que llevarla a pastar. No obstante, a los pocos años, todos tenían cabras españolas y exceso de leche, y mayores costes porque están en las 
cuadras. Entonces ya nadie quería recoger la leche porque no sabian qué hacer con ella, y eso es problemático. Por ejemplo, L. me contó que el pobre M. (un querido amigo suyo de un pueblo vecino) había cambiado sus ovejas por cabras y ahora que ya nadie quería leche estaba desesperado, no sabía qué hacer. ¡Venderlas no podía porque entonces las habría vendido! L. en su momento le había dicho: "déjalo estar, compra más ovejas, no cabras, porque manejar 800 ovejas o mil ovejas no te cambia nada ipero al menos tienes algo seguro!". Hoy le pedí que me contara cómo le iba a M. y me dijo que le iba un poco mejor porque en su pueblo, los 7-8 que tienen cabras han decidido reunirse para hacer un frente común y ver si venden juntos esa leche de cabra. Quizá Granarolo u otra empresa local la quiere... en fin, ahora solo toca conseguir negociar el precio. Luego L. me dice "P., que en cambio es más astuto, se habia olido hace unos años lo de invertir en cabras españolas pero desde que vio que las cosas no iban bien, sin esperar a que llegara una situación en la que tuviera que malvender las cabras, ¡se libró de ellas! ¡Es más listo!” (Diario de campo, Cagliari, sur de Cerdeña, 19 septiembre 2016, conversación telefónica con L.)

La modernización y los componentes agropastorales tradicionales coexisten por tanto en un equilibrio inestable dentro de un registro doble (expansión/resistencia), mediante el cual los pastores amplían sus márgenes de maniobra y multiplican las formas de anclaje y contención de la incertidumbre. En este horizonte a corto plazo, la una también implica la otra. En las fases de crecimiento económico, el pastor naturalmente tiende a expandirse y, como muchos dicen, "mejorar su vida" en comparación con lo que ha vivido anteriormente:

El día 22 se reunió el Movimiento de Pastores Sardos en Sindia. Yo no pude asistir pero me enteré de que E. sífue e intervino. Hablé por teléfono con M., G. y R., a quienes les sorprendió su determinación. Solo que M. por teléfono me dijo que él no comparte el discurso de producir menos (para resolver la crisis). Me dice: "yo quiero producir más, con el pastoreo extensivo, claro, ipero quiero ir siempre a mejor! Durante años nos dijeron que debíamos producir, la gente ha invertido, comprado terrenos, iconstruido cobertizos!". Me cuenta que en su explotación ha entrado hace poco su hijo, que quería comprar un tractor, expandirse. Él, obviamente, es más cauto, ipero es cierto que debe haber también un estímulo para que estos jóvenes se dediquen al pastoralismo! ¡No se les puede cortar las alas! (Diario de campo, Cagliari, sur de Cerdeña, 24 abril 2017, conversación telefónico con M.)

Por otra parte, este comportamiento es comprensible: para el pastor, la explotación y los terrenos representan esa materialidad firmemente proyectada sobre el territorio con la que hacer frente a las crisis provocadas por la incertidumbre. Disponer de los terrenos es un factor estratégico para "salir a flote" por diversos motivos. En primer lugar, reduce la dependencia de la compra de insumos en el mercado gracias a que pueden llevar a los animales a pastar libremente y a que pueden producir sus propios alimentos y pastizales. 
De hecho, sobre todo en los periodos de reducción de la leche conviene no hacer nada y mandar a los animales a los pastos para no gastar:

N. se reía de los del pueblo de al lado que araban y cultivaban. "Con la leche a 50 céntimos, ¿qué sigues arando? Domenica, tienes que hacerles esa pregunta, ¡métela en la entrevista!". La observación de N. es la misma que hacen otros, también A. de Dualchi me dijo que con la leche tan barata no conviene hacer nada, jvolver al pasto natural y ya! (Diario de campo, notas al margen de la entrevista de N., septiembre 2016)

Tener tierras permite luego calibrar la cantidad diaria de la oveja de forma flexible, ya sea en relación con las exigencias del animal, como con la necesidad de reducir costes, aunque se trate de un recurso fuertemente expuesto a la incertidumbre climática:

D. ¿Cuánto te cuesta la ración de la oveja? La alimentación.

La verdad es que también varía, y te digo por qué. Por ejemplo, ahora, ahora y cuando están lactando o reproduciéndose, la alimentación cambia. Ahora por ejemplo, echo un poco de grano en el prado. Una ración de 300 gramos de pienso por la mañana $y$ por la noche las saco una horita a comer en grano del prado, ¡las espigas! ¿Sabes? Cuando las ordeño, las ordeño dos veces, y les doy, qué sé yo, 400, depende del pasto que tenga, de la hierba... Varía, en general les doy medio kilo al día de media, y luego hay periodos en los que la hierba está saliendo, tiene proteínas, así que lo dejo, ¿sabes? O cambio de tipo de pienso, en general doy 500, pero ahora estoy dando 300, depende siempre del tipo de pasto que tengas. Pero si hay un año que se da bien la cosa, consumo menos, y si el año es malo, ipues consumo más!

¿Y el pasto este año cómo está siendo?

¡Malo, malo! No ha llovido nada, yo me he salvado porque sembré unos pastizales y porque también tengo vacas y no solo ovejas, así que he podido salir a flote más o menos, pero el año ha sido malísimo, tanto en otoño como en primavera, aunque tampoco ha sido así en todos lados. ¡La primavera ha estado floja! (primavera 2017, entrevista a ganadero, centro de Cerdeña)

Finalmente, los terrenos encarnan la posibilidad de un ingreso fijo gracias a los pagos de la PAC, que son por hectárea. Dichos ingresos pueden maximizarse en última instancia si se gestionan los terrenos en función de las medidas:

D. Fuimos de los primeros en meternos en la agricultura ecológica en Cerdeña, en 1994, jesa fue la primera vez! [...] ; De los pastores fuimos los primeros! [...] yo y otros nueve amigos de mi pueblo, Bitti.

¿Por qué te registraste en la agricultura ecológica?

D. [...] ¡buscaba subvenciones! ¡Seguro! ¡No hay otro motivo! ¡Eso funciona! [...] Buscábamos financiación... [...] 
¿Y ahora solo te dedicas a la agricultura ecológica?

D. Eh, ¡no! ¡Muchos lo han dejado! ¡Yo no puedo hasta 2018! Porque si te registras como "ecológico" en el régimen de la PAC, jestás obligado a seguir cinco años! Si lo dejas antes, ¡has de devolver todos los subsidios! Si hubiera podido, lo habría dejado yo también, ipero estoy obligado a seguir hasta 2018! [...]

¿Y por qué quieres dejar la agricultura ecológica?

D. Porque hoy día es mejor hacer como T. (otro amigo pastor) que ha decidido "proteger el suelo" en vez de la agricultura ecológica, así alternas los cultivos o aras una vez cada 5 años. Esta práctica es menos costosa que la agricultura ecológica. [...] Con la agricultura ecológica siempre tienes que arar productos ecológicos iy eso hoy es un riesgo! (se refiere a que la sequía y el mal tiempo pueden arruinar la cosecha). Con la protección del suelo, el pago de este año es de 243 euros por hectárea... ¿y eso para arar una vez cada cinco años? (Septiembre 2016, entrevista a ganadero, Bitti, centro de Cerdeña).

El uso instrumental de las oportunidades de financiación es una verdadera estrategia de resiliencia propia en un contexto en el que las explotaciones familiares suponen la inversión de una vida, en el sentido en que no hay alternativas. Así y todo, el pastoralismo sigue siendo una actividad arriesgada y costosa:

F. ; Ya verás que el año que viene la leche empieza a 50!

Pero es que 50 es bajísimo, ¡ni siquiera cubre los costes para producirla!

F. ¡Eh! ¿Porque a 80 crees que sí los cubres?

¡No lo sé! ¡Vosotros lo sabéis! ¿Cuánto te cuesta producirlo?

F. ¡No! ¡No cubres gastos ni siquiera a 80! ¿Pero qué puedes hacer? Tú que llevas treinta años invirtiendo en el campo, has comprado terrenos, maquinaria, tractores, ¿y ahora qué? ¿Te vas a trabajar a la obra? Vas a... Eh... ¿Qué haces?

[...] Muchos no me dicen cuánto les cuesta producir leche, ¡no quieren decirlo!

F. No, pero sabes qué pasa, que no se sabe, no lo sabes, porque mucha gente, y yo el primero, no hacemos las cuentas al minuto, jal detalle no, al menos! Porque para valorar cuánto te cuesta un litro de leche, tienes que contarlo todo: luz, agua, pienso, neumáticos de las máquinas, combustible, eh, la copa que se me rompió el otro día también la tengo que meter, todo lo que has metido, todo lo que ha salido de este trabajo. Porque si eres asalariada, todo ese salario se ve de dónde sale. Sin embargo, nosotros tendemos a anotar en detalle los gastos más grandes y las nimiedades no las incluimos, ipero a nivel de gastos acaba siendo mucho! Así que en mi opinión, ¡los 80 céntimos actuales no son suficientes! ¡Para producir un litro de leche! Mi seguro, el seguro de la máquina, el de la explotación, ahora hay mil cosas... Eh... los medicamentos... todo lo que no importa en el campo, todas las cosas superfluas, no superfluas, que no son necesarias, y tal vez no las incluyes como gastos, pero en mi opinión, ni siquiera un euro sería suficiente para cubrir los gastos que tenemos hoy. 
Claro que es una hipótesis, iporque no hacemos las cuentas! (se gira a E. otro pastor): ¿Tú cuentas todo eso?

E. iNo!

F. ¡Y creo que nadie lo hace! ¡Creo que el $80 \%$ no lo hará!

$[\ldots]$

E. ¡Las cuentas se hacen a final de año cuando te ves teniendo que cubrir costes y gastos que no consigues cubrir! [...] porque si tienes en cuenta que ganas 30-40 céntimos menos que el año pasado por litro de leche, en una finca ipuedes verte con 15-20 mil euros menos a final de año!

F. ¡Como mínimo! Pero el problema es que nosotros tenemos primas comunitarias no indiferentes, unos más, unos menos, y consigues salir a flote bien... pero tranquila que si no existieran, ¡del fruto de la oveja habrían quedado pocos! ¡Pocos pastores y pocas ovejas! ¡Es mi opinión! [...] Nosotros tenemos una entrada no indiferente, quién más, quién menos, a nivel de primas comunitarias iy por eso estamos saliendo a flote! A veces también pasa que las tierras son heredadas, iy ese se apaña muy bien incluso sin las ayudas! Por otro lado está el que trabaja en el sector lechero, alquila las tierras y encima debe producir para rendir; con un litro de leche a 60 o 50 no va a ningún lado. [...] Si tienes prima porque cultivas el terreno, puedes pasar de la leche, con la prima cubrirás los gastos de la finca je irás igual de bien! (Octubre 2016, discusión entre dos pastores sobre la crisis del precio que se planteaba para 2017, Sarule, centro de Cerdeña)

\section{RESILIENTES, SÍ... ¿PERO HASTA QUÉ PUNTO?}

En el apartado anterior se evidencia cómo en la explotación pastoral existe un equilibrio delicado entre la modernización y el modelo agropastoral tradicional, entre empresa orientada a los beneficios e incrementos productivos y empresa campesina, con el objetivo de la reproducción y la subsistencia.

Con miras a corto plazo, los ganaderos incorporan componentes del modelo agropastoral tradicional (ganadería extensiva y pastoreo, trabajo familiar, autoproducción para autoconsumo, reutilización de los factores productivos, cultivo mixto y multiactividad) con las oportunidades que ofrece la modernización. Por una parte, las primas de la PAC y las medidas de financiación previstas en los planes de desarrollo rural, utilizados de forma flexible e instrumental para fortalecer la posición de la finca. Por otra parte, las innovaciones para mejorar la crianza y los niveles productivos, como la selección genética, la introducción de razas más lucrativas, la utilización de piensos concentrados y ensilajes, la construcción de establos modernos con carriles de alimentación y mezcladoras.

Los pastores han aprendido a gestionar la incertidumbre vinculando sus decisiones a un futuro contingente en el que se alternan momentos en los que se expanden para consolidar la explotación y fases en las que el objetivo de los beneficios pasa a segundo plano. 
En ambos casos, se resaltan, dependiendo de las necesidades, tanto los componentes tradicionales de la explotación como los más "modernos".

No obstante, la larga vida de la crisis de precios iniciada en 2017 y que sigue actualmente en efecto está poniendo de relieve que la capacidad de resiliencia de las explotaciones ganaderas es cada vez menor. Los procesos de modernización están destruyendo los componentes tradicionales del modelo agropastoral, reduciendo su capacidad de resistir a las crisis, exponiéndolo cada vez más y aumentando su dependencia a las dinámicas de los mercados internacionales.

La familia, como cámara de compensación de los mecanismos productivos de la explotación, hace frente a cada vez más dificultades, debido a las tendencias demográficas negativas que azotan a la isla de Cerdeña (despoblación, envejecimiento, escasa natalidad). Y eso queda demostrado cuando observamos que recurren a trabajadores extranjeros para cubrir las carencias de mano de obra (Farinella y Mannia, 2017; 2018). Aquí basta subrayar que según el Consejo de Investigación Agrícola (CREA) (2017: 168169), los trabajadores comunitarios de la cría de ganado sarda eran 1.084 en 2015, y los extracomunitarios 283.

Actualmente se ve que la obligación de modernizarse, incentivada por las políticas, ha generado efectos contradictorios que desvirtúan cada vez más las características de la ganadería sarda, concretamente el pastoreo extensivo. En las zonas de llanura, principalmente adaptadas a la producción de leche de bajo coste para la industria, los ganaderos tienen una clara especialización y han reducido considerablemente las actividades complementarias para la producción del autoconsumo que desde siempre han supuesto un refugio en los momentos de crisis. La selección genética ha dado ovejas más productivas, pero también más débiles y peor adaptadas al prado natural, que es el recurso que había permitido que la ganadería sarda fuera al fin y al cabo una actividad barata, poco costosa y adaptada a un territorio marginal con pocas oportunidades. Los ganaderos cada vez dependen más de la compra de piensos y otros insumos necesarios para producir.

N. Para nuestros abuelos, nuestros tíos, una oveja que te daba un cuarto de leche cuando llegaba a los 10-12 años les parecía una niña, ipero nuestras ovejas ya no sirven a los 4-5 años!

M. ¡Ya están exprimidas!

$N$. Porque empiezas a ordeñarla en diciembre y dejas de ordeñar en septiembre. Las mandas en secado porque ya no pasa el camión de la leche, jsi pasa el camión sigues ordeñando hasta octubre! [...] Yo este año el 25 de agosto las mandé en secado iporque ya no pasó más el camión de la leche! [...] Aquí si no les das pienso en este periodo (pienso comprado, nota propia)... si no les das pienso al año ya no te quedan ovejas, ¡al menos las mías son así! 
M. ¡Son todas así! [...]

N. Al principio cuando había quedadas de pastores... nosotros por ejemplo entre pastores nos decíamos “¿a cuánto tienes las ovejas?» ¡Y decíamos litro y medio! ¿¿Sabes qué decían antes los pastores?! "3 por litro”, es decir tres ovejas para hacer un litro, ¿sabes?

M. ¡Pero los gastos eran menores!

N. Es decir, tenían ovejas, 300 ovejas que igual sacaban 100 litros de leche como mucho

M. Pero de esos 100 litros, 80 te los sacabas limpios, solo gastabas 20 en piensos N. ¡Y ni siquiera, M.!

M. ¡Ganaban más a final de año!

¿Y ahora por qué no conviene volver a ese sistema?

M. ¡No! No es que no convenga, ;conviene volver a ese sistema!

N. ¡Nos han obligado! No, conviene, conviene, pero nos han obligado, jahora lo entendemos!

M. Conviene pero tienes que cambiar todo el mecanismo...

B. ¡Tienes que cambiar la genética!

M. No es solo la genética, ¡tienes que cambiarlo todo!

(Conversación entre ganaderos, centro de Cerdeña, primavera 2017)

La necesidad de aumentar el nivel de producción y reducir los costes por unidad de producto impulsada por el modelo de producción industrial del pecorino romano ha llevado a las explotaciones ganaderas a la intensificación, concentración y estandarización.

Algunos hicieron como yo y dieron el salto al principio para sacar más de los animales y luego al final se dieron cuenta de que las cuentas no salían... producir leche a bajo precio y tratar de sacar el máximo de las ovejas, explotar a los animales como si fueran máquinas al final no daba nada... nada, al final te encontrabas con un animal que moría dos años antes, costes de producción altísimos, para luego no conseguir nada. En mi opinión, lo mejor es cerrar el sector (hacer queso), porque si no, no consigues nada. Estás haciendo el trabajo sucio de otros [...] De media una oveja vive 10-11 años bien, si no ha tenido problemas a lo largo de su vida, [...] y si las presionas, ¡les estás poniendo baches en el camino! [...] Y luego los costes, para obtener esos 100 gramos adicionales de leche, ¿cuánto tienes que gastar? [...] De hecho, ya te dije que como producción he dado un paso atrás, pero grande, porque antes quería sacar el máximo de la producción de cada cabeza de ganado. Si esa oveja no me daba el máximo, no debía estar ahí, iy ahora ya no es así! [...] En los años noventa, (los técnicos regionales, nota propia) venían a darnos lecciones de cómo convertirnos en pastores modernos. Nos decían dónde producir, qué cantidades, pero en Cerde $e^{\tilde{n} a}$ no estamos hechos para hacer esas cantidades iporque el territorio no lo permite! 
Con frecuencia la explotación es muy pequeña en términos de extensión, y tienes que recurrir a comprar piensos y provisiones fuera de la finca. Eso se lo puede permitir quien tiene tierras y por tanto cría a tanto ganado como puede permitirle su terreno, pero allí se creaban explotaciones de pocas hectáreas con miles de cabezas que han de comprar fuera $90 \%$ de lo que necesitan para la explotación. No debería ser as ${ }_{i}$, debería ser al revés, [...] e $e_{1} 90 \%$ lo produces tú y el $10 \%$ lo compras, pero bueno, llegas a un punto medio iy con suerte llegas a producir el $60 \%$ ! (Abril 2017, entrevista a ganadero, Siamanna, sur de Cerdeña)

Incluso la explotación moderna de los terrenos lleva a sustituir donde se puede el pasto natural por monocultivos de pastizales y forrajeras a bajo coste. Eso disminuye la biodiversidad ambiental que hacía que la leche sarda fuera sabrosa y distinguible de forma natural. Esto es muy querido para los ganaderos que siguen transformando leche y que para hacer queso prefieren leche de oveja de pastos silvestres:

A. me dice que al final solo les da pienso a las ovejas para meterlas en la ordeñadora, pero que de resto comen pastos. Las que usa para hacer leche comen siempre en pastos naturales y no cultivados. iSe nota la diferencia en el queso! Su padre se mete en la conversación y dice que el mejor queso sale de los pastos silvestres. Ahí las ovejas comen de todo y el queso sale mejor que si comen donde solo hay un tipo de hierba. A. me dice que donde hacen queso no usan ni heno ni forraje. El queso lo absorbe todo, incluso los olores de la bodega. Mientras que por ejemplo en la cámara frigorifica no hay olores, así que el queso no sale igual que cuando se madura de forma natural. (Diario de campo, 9 de abril 2017, Orotelli, centro de Cerdeña).

Las presiones para modernizarse están socavando de forma irreversible los componentes del pastoralismo que, anclándolo al territorio, lo protegían de la inestabilidad del mercado y de la volatilidad del precio de la leche, la cual hoy día está cada vez más acentuada. Las fluctuaciones del precio de la leche son cada vez más frecuentes. En un contexto así, la capacidad de resiliencia del modelo agropastoral parece cada vez más limitada, y las estrategias de adaptación que los pastores han puesto en práctica en el campo para resistir a las fases de crisis y volver a producir en las de crecimiento son cada vez menos eficaces para hacer frente a esta nueva cuestión agraria, que también cobra importancia en este pequeño rincón de Cerdeña.

Si te fijas, antes se producía de tal manera que la ovejita te daba ese litro de leche y tenía valor. Con él se hacía queso y este tenía un valor. Ahora si producen tres o cuatro litros... no sé cuánto llegan a producir estas superovejas, y alrededor de estos litros de leche hay toda una maquinaria, un camión que los transporta, establecimientos que lo elaboran, luego hace falta gastar para eliminar los residuos, etc. Y todo eso es como si fuera agua, porque luego te da un producto uniforme que se produce en todas partes. La leche que producimos nosotros antes tenía un valor porque tenía 
un perfume; ahora produces una leche que producen en cualquier parte del mundo porque las metes en el cobertizo, les das pienso... Nosotros hemos perdido lo que le daba valor a la leche que se producía en Cerdeña [... y yo cuando veo a los pastores que se gastan miles de euros para comprar un macho seleccionado que produce cada vez más para hacer una leche que se transforma en establecimientos que hacen el mismo queso en Argentina o en Rumanía, ¿para qué sirve que estemos en una isla, que tengamos este clima, estas hierbas, estas especies de animales que nos permitían hacer un producto que nadie tenía e introducirlo en el mercado como el producto de nuestra isla con estas características y a ese punto eres competitivo porque aportas calidad? (Julio 2017, entrevista a ganadera, Ittiri, noroeste de Cerdeña) 


\section{BIBLIOGRAFÍA}

Angioni, Giulio (1989) I pascoli erranti. Antropologia del pastore in Sardegna. Napoli: Liguori.

Chayanov, Alexander V. (1986-reprinted) [1922]. The Theory of the Peasant Economy. Manchester: Manchester University Press.

Consorzio per la tutela del Pecorino Romano Dop (2015) Piano di regolazione dellofferta delpecorino romano dop. Assemblea dei Soci del 13/5/2015. https://www.pecorinoromano. com/application/files/5514/9069/8509/Piano-Regolazione-Offerta-Pecorino-RomanoDOP.pdf [Consultado el 20 de febrero de 2018]

CREA (2017) Annuario dell'Agricoltura italiana 2015. Vol. LXIX, Roma: CREA.

De Certeau, Michel (1990) Linvention du quotidien. 1 - Arts de faire. Paris: Gallimard.

Di Felice, Maria Luisa (2011) "La "rivoluzione" del pecorino romano. Modernità e tradizione nell'industria casearia sarda del primo Novecento". En Antonello Mattone y Pinuccia Simbula (coords.) La pastorizia mediterranea. Storia e diritto (secoli XI-XX). Roma: Carocci, pp. 949-993.

(2019) "Le ragioni e la lotta dei pastori sardi". Gli Asini, n.6, pp.17-22.

(2019b). "The case of the Pecorino Romano dairy production chain in Sardinia, Italy". En Marinella Migliorini (coord.) FOOD-TRACK. A transparent and traceable supply chain for the benefit of workers, businesses and consumers: the role of a multisectoral approach to industrial relations and corporate social responsibility. Roma: CGIL, 130-163.

_ (2018) "La pastorizia sarda di fronte al mercato globale", Meridiana n.93, pp.113134.

(2018) " "Mi chiamo Serban e non sono il romeno di nessuno, sono il romeno di me stesso". Pratiche di assoggettamento e soggettivazione tra pastori sardi e servi pastori romeni". Etnografia e Ricerca qualitativa n.3. pp. 405-426.

(2017) "Migranti e pastoralismo. Il caso dei servi pastori romeni nelle campagne sarde". Meridiana n.88, pp.175-196.

(2020) "Una modernizzazione "adattiva": la famiglia-azienda pastorale in Sardegna tra filiere capitalistiche e cooperazione”, Artículo aún no publicado.

Idda, L.; Furesi, R. y Pulina, P. (2010) Economia dellallevamento ovino da latte. Milano: FrancoAngeli

Idda, L.; Furesi, R. y Pulina, P. (2010b) "Lallevamento ovino in Sardegna tra crisi di mercato e politiche per il rilancio". Agriregionieuropa (6)23, pp.65-68.

ICE, http://actea.ice.it/ 
ISMEA (2019) Settore ovicaprino, Scheda di settore http://www.ismeamercati.it/lattierocaseari/latte-derivati-ovicaprini [Consultado el 15 de enero de 2020]

Istat (2013) Indagine sulla struttura delle aziende agricole www.agri.istat.it [Consultado el 12 de febrero de 2019]

(2017 Indagine sui prodotti lattiero-caseari www.agri.istat.it [Consultado el 12 de febrero de 2019]

Laore (2013). Comparto ovi-caprino e zootecnia regionale, dati strutturali, Cagliari: Regione Autonoma della Sardegna.

Le Lannou, Maurice (1979) Pastori e contadini di Sardegna. Cagliari: Edizioni della Torre. Mannia, Sebastiano (2014) In tràmuta. Antropologia del pastoralismo in Sardegna. Nuoro: Il Maestrale.

Mattone, Antonello y Simbula, Pinuccia (coords.) (2011) La pastorizia mediterranea. Storia e diritto (secoli XI-XX). Roma: Carocci.

Meloni, Benedetto (1984) Famiglie di pastori: continuità e mutamenti in una comunità della Sardegna Centrale 1950-1970. Torino: Rosenberg \& Sellier.

Benedetto (1996) Ricerche locali. Comunità, economia, codici e regolazioni sociali. Cagliari: CUEC.

(2015) "L'evoluzione dei modelli agropastorali in Sardegna dagli anni cinquanta ad oggi”. En Luciano Marrocu, Francesco Bachis y Valeria Deplano (coords.) La Sardegna contemporanea. Roma: Donzelli, pp.447-473.

(2015b) "Pastoralismo e filiera lattiero casearia, tra continuità ed innovazione: unanalisi di caso". Meridiana, n.84, pp.163-188.

Murru Corriga, Giannetta (1990) Dalla montagna ai campidani. Sassari: EDES.

Nori, Michele (2019) Herding through Uncertainties - Principles and practices. Exploring the interfaces between pastoralists and uncertainty. Results from a literature review. Robert Schuman Centre for Advanced Studies Research Paper No. RSCAS 2019/69. http://dx.doi.org/10.2139/ssrn.3457237 [Consultado el 11 de diciembre de 2019]

Ortu Gian Giacomo (1988) "La transumanza nella storia della Sardegna". Mélanges de l'Ecole française de Rome. Moyen-Age, Temps modernes (100)2, pp. 821-838.

Paoli, Jean Christophe (2018) Printzipàles e pastori sardi. Origine e trasformazione di un allevamento ovino mediterraneo. Cagliari: Condaghes.

Ploeg van der, Jan Douwe (2008) The new peasantries: struggles for autonomy and sustainability in an era of empire and globalization. New York: Routledge. 
Ploeg van der, Jan Douwe (2013) Peasants and the art of farming: A Chayanovian manifesto. Winnipeg, NS: Fernwood Pub.

Ploeg van der, Jan Douwe y Roep, Dirk (2003) "Multifunctionality and rural development: the actual situation in Europe". En Guido Van Huylenbroeck y Guy Durand (coords.) Multifunctional Agriculture. A new paradigm for European agriculture and Rural Development. Burlington, VT (USA) e Aldershot (UK): Ashgate.

Scoones, Ian (2019) What is Uncertainty and Why Does it Matter?, STEPS Working Paper 105, Brighton: STEPS Centre https://opendocs.ids.ac.uk/opendocs/ handle/20.500.12413/14470 [Consultado el 4 de enero de 2020]

Simula, Giulia (2019) Should we cry over spilled milk? The case of Sardinia. https://pastres. org/2019/02/15/should-we-cry-over-spilled-milk-the-case-of-sardinia/ [Consultado el 10 de septiembre de 2019] 